\title{
Voltage Stability Analysis of Muscat Power System During Summer Weather Conditions
}

\author{
K. Ellithy*, A. Gastli, S. Al-Alawi*, A. Al-Hinai*, and Z. Al-Abri** \\ ${ }^{*}$ Department of Electrical and Electronics Engineering, College of Engineering, \\ Sultan Qaboos University, P.O. Box 33, Al Khod 123, Muscat, Sultanate of \\ Oman, and ${ }^{* *}$ Ministry of Electricity and Water, Muscat Sultanate of Oman.
}

تحليل لسقرار الجهد الكهربائي بشبكة القوى بطسط تحت حالاتطقس الصف

خالد الليثي ، علا الفمطلي ، صالح العلوي ، عامر الهنائي، وزلهر المبري

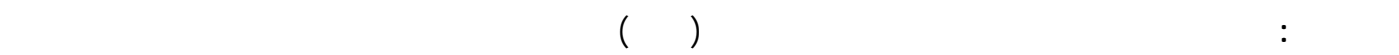

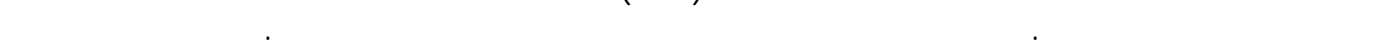

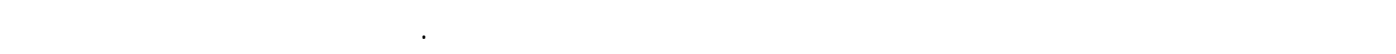

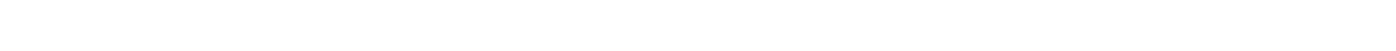

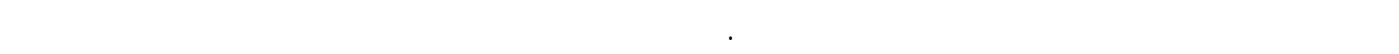

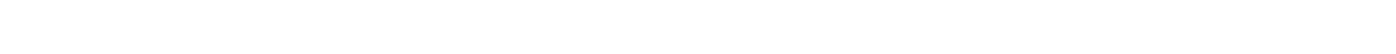

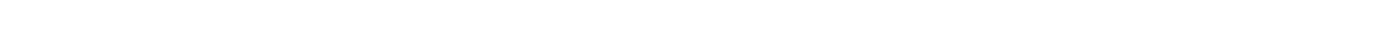

اللشبكة.
\end{abstract}

\begin{abstract}
A systematic and general formulation of a Propagation Simulation Program (PSP) is developed for the coherent field of microwave and millimeter wave carrier signals traversing intermediate layered precipitation media taking into account the random behavior of particle size, orientation, shape and concentration distributions. Based on a rigorous solution of the volumetric multiple-scattering integral equations, the formalism offers the capability of treating the potential transmission impairments on satelliteearth links and radar remote sensing generated by composite atmospheric layers of precipitation in conjunction with the finite polarization isolation of dual-polarized transmitting and receiving antennas. A multi-layered formulation is employed which encompasses an ensemble of discrete particles comprising an arbitrary mixture of ice crystals, melting snow and raindrops that may exist simultaneously along satellite-earth communication paths.
\end{abstract}

KEYWORDS: Muscat Power System, Voltage Stability, Modal Analysis, Q-V curves, P-V curves.

oltage stability problems have been one of the major concerns for electric utilities as a result of

heavy system loading. Voltage stability is the ability of a power system to maintain acceptable steady-state voltage at all buses in the system under normal operating conditions. A power system enters a state of voltage instability (voltage collapse) when a disturbance, an increase in load demand or a change in system conditions, causes a progressive and uncontrollable fall of voltage.

The problem of voltage stability has been experienced by many utilities because of loading their bulk transmission network to their maximum possible capacity to avoid the capital cost of building new lines and generation facilities. Several major network collapses, caused by voltage instability problems, were reported around the world in various countries such as France, Sweden, Japan, Belgium, and USA (Taylor, 1994). Most of the incidents are believed to be related to heavily stressed systems where large amounts of real and reactive power are transported over transmission lines while appropriate reactive power sources are not available to maintain a nominal voltage profile at receiving-end buses.

In recent years, the problem of voltage stability and collapse has attracted considerable attention from power system researchers. Many techniques have been proposed in the literature for evaluating 
and predicting voltage stability. Among these techniques are P-V curves (Pal, 1992; Suzuki et al, 1992), Q-V curves (D'Aquila et al, 1993; Vaahedi et al, 1999; Schluter, 1998; Taylor, 1994), modal analysis (Gao et al, 1992; Morrison et al, 1993; Mansour et al, 1994), minimum singular value (Löf et al, 1993; Liu et al, 1998), sensitivity analysis (Begovic and Phadke, 1992; Fltabo and Dommel 1990), energy function (Overbye and DeMacro, 1995; DeMacro and Overby, 1990), reactive power optimization (Tamura et al, 1982), artificial neural networks (Jesasuray, 1990; El-Keib and Ma, 1995) and neuro-fuzzy networks (Liu and Su, 1998). Large numbers of research papers on power systems voltage stability have been published recently by the IEEE Voltage Stability Working Group (Ajjarapu and Lee, 1998).

Muscat power system supplies power to almost one million people in the capital (Muscat) and its adjacent area in the Sultanate of Oman. There are heavy loaded areas having a voltage stability problem in the system. These load areas are summer peaking and because of heavy use of air conditioning, the loads are weather sensitive. Voltage instability is most likely to occur during periods of summer or abnormal-summer weather. Following the discovery of serious voltage stability problems in some heavy load areas, an intensive effort was undertaken by the Ministry of Electricity and Water of the Sultanate of Oman to find solutions. In this paper, the voltage stability behavior of Muscat power system is analyzed using the modal (eigenvalue) analysis, $\mathrm{Q}-\mathrm{V}$ curves and P-V curves methods. A computer program using MATLAB was developed to analyze the voltage stability of a large power system. The modal analysis method as well as P-V curves and Q-V curves were part of the program. The modal analysis was used to identify the weakest load buses in the system while the P-V curves and Q-V curves were used to determine the MW and MVAr margins from the operating point to the voltage instability point.

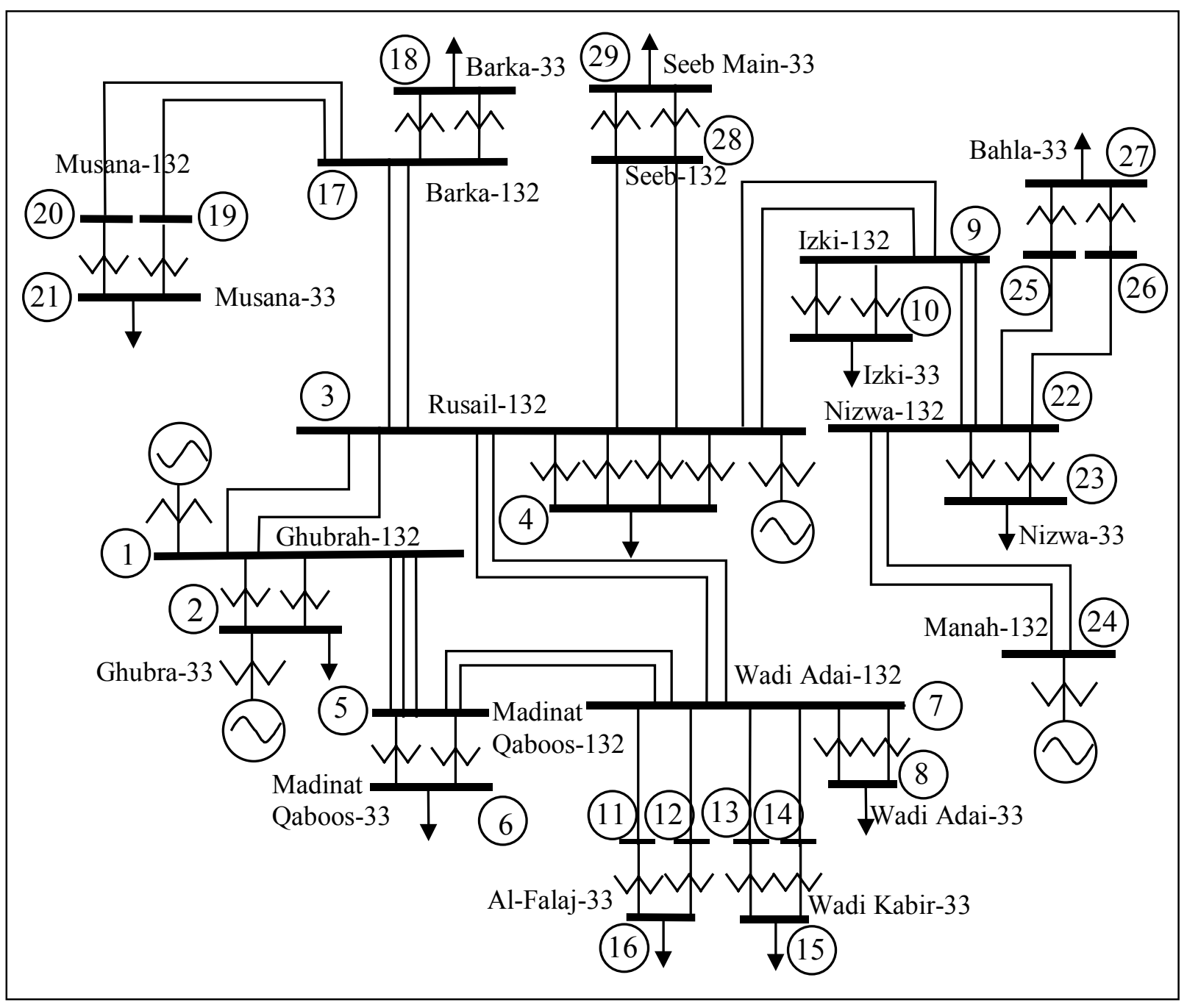

Figure 1. Single line diagram of Muscat power system 


\section{VOLTAGE STABILITY ANALYSIS OF MUSCAT POWER SYSTEM}

\section{Describtion of Muscat Power System}

The single line diagram of Muscat power system is shown in Figure 1. Muscat has a mean annual temperature of nearly $30 \mathrm{C}^{\circ}$ and a summer daily temperature above $40 \mathrm{C}^{\circ}$. These high temperatures have a strong effect on the electrical load demand, especially in the summer season, since $80 \%$ of the load in the system during the summer is for air conditioning. This high demand for electric load during the summer can lead to various problems such as voltage instability.

\section{Power-Flow Problem}

The power-flow problem solves the complex matrix equation:

$$
\bar{I}=\bar{Y} \bar{V}=\frac{\bar{S}^{*}}{\bar{V}^{*}}
$$

where $\bar{I}$ is the nodal current injection matrix, $\bar{Y}$ is the system nodal admittance matrix, $\bar{V}$ is the unknown complex node voltage vector and $\bar{S}$ is the apparent power nodal injection vector representing the specified load and generation at nodes where $\bar{S}=P+j Q$. The superstar refers to the complex conjugate. The Power-flow (also called load-flow) problem is very closely associated with voltage stability analysis. Power-flow solution is an essential tool for voltage stability evaluation. Much of the research on voltage stability deals with power-flow computation method.

The Newton-Raphson method (Taylor, 1994) is the most general and reliable algorithm to solve the powerflow problem. From equation (1), we can write the equation for node $k$ (bus $k$ ) as

$$
\begin{gathered}
\bar{I}_{k}=\sum_{m=1}^{n} \bar{Y}_{k m} \bar{V}_{m}, \\
P_{k}+j Q_{k}=V_{k} I_{k}^{*}=\bar{V}_{k} \sum_{m=1}^{n}\left(\bar{Y}_{k m} \bar{V}_{m}\right)^{*} .
\end{gathered}
$$

using the following notation

$$
\bar{V}_{k}=V_{k} e^{j \theta_{k}}, \quad \bar{V}_{m}=V_{m} e^{j \theta_{m}}, \quad \bar{Y}_{k m}=Y_{k m} e^{j \gamma_{k m}} .
$$

Equation (3) becomes

$$
P_{k}+j Q_{k}=\sum_{m=1}^{n} Y_{k m} V_{k} V_{m} \cos \left(\theta_{k}-\theta_{m}-\gamma_{k m}\right)+j \sum_{m=1}^{n} Y_{k m} V_{k} V_{m} \sin \left(\theta_{k}-\theta_{m}-\gamma_{k m}\right)
$$

The mismatch power at bus $\mathrm{k}$ is given by

$$
\begin{aligned}
& \Delta P_{k}=P_{k}^{s c h}-P_{k} \\
& \Delta Q_{k}=Q_{k}^{s c h}-Q_{k}
\end{aligned}
$$

Where $P_{k}^{s c h}$ and $Q_{k}^{s c h}$ are the net scheduled active and reactive powers injected into the network at bus k, respectively. The $P_{k}$ and $Q_{k}$ are calculated from equation (4).

The Newton-Raphson method solves the partitioned matrix equation:

$$
\left[\begin{array}{l}
\Delta P \\
\Delta Q
\end{array}\right]=J\left[\begin{array}{l}
\Delta \theta \\
\Delta V
\end{array}\right]
$$

where $\Delta P$ and $\Delta Q$ are mismatch active and reactive power vectors, $\Delta V$ and $\Delta \theta$ are unknown voltage magnitude and angle correction vectors and $J$ is Jacobian matrix of partial derivative terms calculated from equation (4).

\section{Voltage Stability Evaluation}

The modal (eigenvalue) analysis (Gao et al, 1992; Morrison et al, 1993; Mansour et al, 1994), Q-V curves (D'Aquila et al, 1993; Vaahedi et al, 1999; Schluter, 1998) and P-V curves (Pal, 1992 and Suzuki et $a l, 19924)$ methods are used for voltage stability evaluation and assessment of Muscat power system. These 
methods are used to identify the probable weak load areas, which could lead the system to voltage instability.

MODAL ANALYSIS: The modal (eigenvalue) analysis provides a powerful analytical tool for determining both proximity to, and mechanism of, voltage instability. In the modal analysis method, the system reactive power variation sensitivity to incremental change in bus voltage magnitude is found and then weak modes (weak buses) of the system are identified. The modal analysis uses the power-flow Jacobian matrix.

Equation (5) can be rewritten as

$$
\left[\begin{array}{l}
\Delta P \\
\Delta Q
\end{array}\right]=\left[\begin{array}{l}
J_{11} J_{12} \\
J_{21} J_{22}
\end{array}\right]\left[\begin{array}{l}
\Delta \theta \\
\Delta V
\end{array}\right]
$$

By letting $\Delta P=0$ in equation (6), we can write

$$
\Delta P=0=J_{11} \Delta \theta+J_{12} \Delta V
$$

or

$$
\Delta \theta=-J_{11}^{-1} J_{12} \Delta V
$$

and

$$
\Delta Q=J_{21} \Delta \theta+J_{22} \Delta V
$$

Substitute equation (7) in (8), to get

$$
\Delta Q=J_{R} \Delta V
$$

where

$$
J_{R}=\left\lfloor J_{22}-J_{21} J_{11}^{-1} J_{12}\right\rfloor
$$

$J_{R}$ is a reduced Jacobian matrix of the system.

Equation (9) can be written as

$$
\Delta V=J_{R}^{-1} \Delta Q
$$

The matrix $J_{R}$ represents the linearized relationship between the incremental changes in bus voltage $(\Delta V)$ and bus reactive power injection $(\Delta \mathrm{Q})$. The System voltage is affected by both real and reactive power variations. Eliminating the real power $(\Delta \mathrm{P}=0)$ and angle part from the system equation (6), allows us to focus on the study of the reactive demand and supply problem of the system as well as minimize computational effort by reducing dimensions of the Jacobian matrix $\mathrm{J}$.

Voltage stability characteristics are analyzed by computing eigenvalues and eigenvectors of the reduced order Jacobian matrix $J_{R}$. The eigenvalues of matrix $J_{R}$ identify different modes through which the system could become voltage unstable. The magnitude of the eigenvalues provides a relative measure of proximity to instability. The eigenvectors, on the other hand, provide information about to the mechanism of loss of voltage stability.

Eigenvalue analysis of $J_{R}$ results in the following:

$$
J_{R}=\Phi \Lambda \Gamma
$$

where $\Phi$ is the right eigenvector matrix of $\mathrm{J}_{\mathrm{R}} \Gamma$ is the left eigenvector matrix of $\mathrm{J}_{\mathrm{R}}$ and $\Lambda$ is the diagonal eigenvalue matrix of $\mathrm{J}_{\mathrm{R}}$. Equation (11) can be written as

$$
J_{R}^{-1}=\Phi \Lambda^{-1} \Gamma,
$$

where $\Phi \Gamma^{-1}=I$. Substituting equation (12) in (10), leads to

$$
\Delta V=\Phi \Lambda^{-1} \Gamma \Delta Q
$$


or

$$
\Delta V=\sum_{i} \frac{\Phi_{i} \Gamma_{i}}{\lambda_{i}} \Delta Q
$$

where $\lambda_{\mathrm{i}}$ is the $\mathrm{i}^{\text {th }}$ eigenvalue, $\Phi_{\mathrm{i}}$ is the $\mathrm{i}^{\text {th }}$ column right eigenvector and $\Gamma_{\mathrm{i}}$ is the $\mathrm{i}^{\text {th }}$ row left eigenvector of matrix $J_{R}$. Each eigenvalue $\lambda_{i}$ and corresponding right and left eigenvectors $\Phi_{i}$ and $\Gamma_{i}$, define the $i^{\text {th }}$ mode of the system. The $i^{\text {th }}$ modal reactive power variation is defined as:

$$
\Delta Q=K_{i} \Phi_{i}
$$

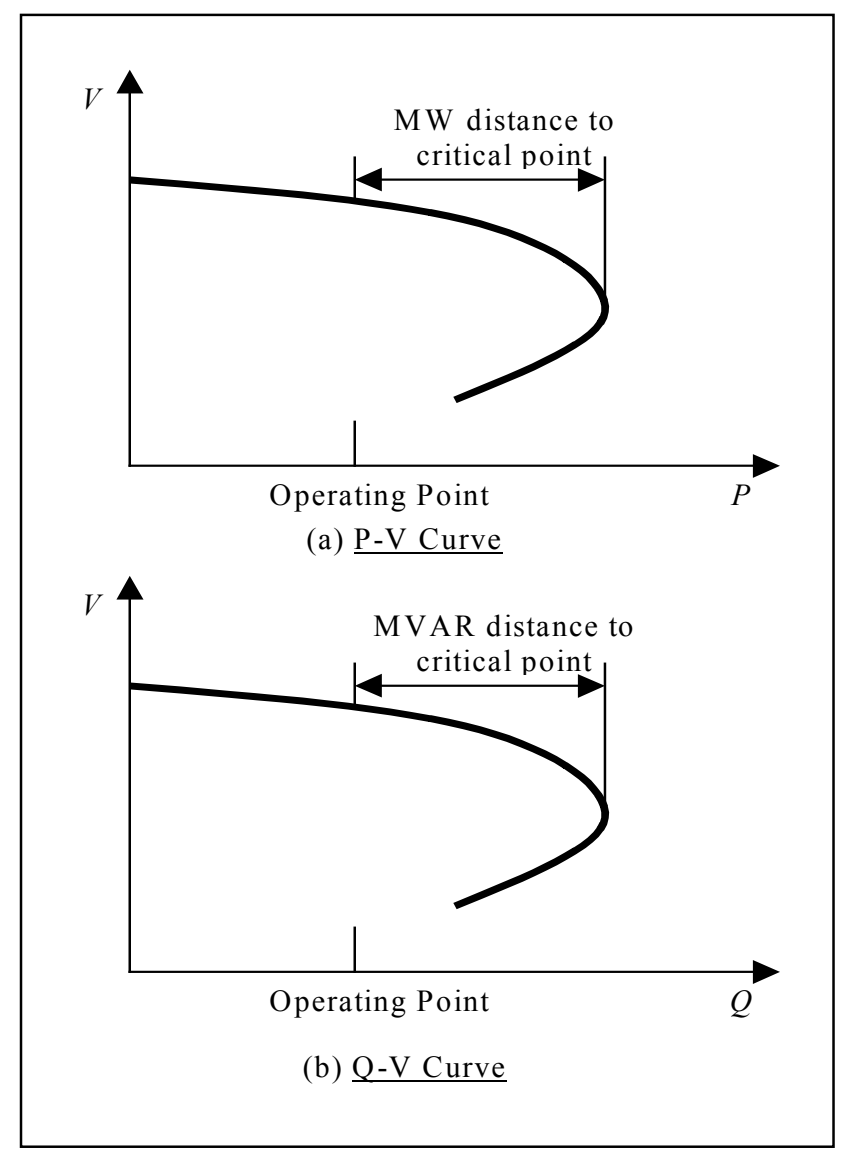

Figure 2. MW and MVAr margin to voltage instability

where $K_{i}$ is a scale factor to normalize vector $\Delta Q_{i}$ so that

$$
K_{i}^{2} \sum_{j} \Phi_{j i}^{2}=1
$$

with $\Phi_{j i}$ being the $\mathrm{j}^{\text {th }}$ element of $\Phi_{i}$. The corresponding $\mathrm{i}^{\text {th }}$ modal voltage variation is

$$
\Delta V=\frac{1}{\lambda_{i}} \Delta Q
$$

If $\lambda_{i}=0$, the $i^{\text {th }}$ modal voltage will collapse because any change in that modal reactive power will cause infinite modal voltage variation. If $\lambda_{i}>0$, the $i^{\text {th }}$ modal voltage and $i^{\text {th }}$ reactive power variation are along the same direction, indicating that the system is voltage stable. If $\lambda_{\mathrm{i}}<0$, the $\mathrm{i}^{\text {th }}$ modal voltage and the $\mathrm{i}^{\text {th }}$ 
reactive power variation are in opposite directions, indicating that the system is voltage unstable. "A system is voltage-stable if the eigenvalues of $J_{R}$ are all positive". It is impractical and unnecessary to evaluate all the eigenvalues of a large power system because it is known that once the minimum eigenvalue becomes zero the system Jacobian becomes singular and voltage instability occurs. So the eigenvalues of importance are the critical eigenvalues of the reduced Jacobian matrix $J_{R}$. An algorithm for calculating the minimum eigenvalue and the corresponding left and right eigenvectors has been developed in Stewart and Jennings (1981).

IDENTIFICATION OF THE WEAK LOAD BUSES: Certain eigenvalues, which lead to voltage instability, need to be monitored more closely. The appropriate definition and determination as to which load bus (load area) significantly participates in the selected modes become very important. This requires tools for identifying load buses that are significant in producing the selected modes. Verghese et al (1982) has suggested a dimensionless measure of state variables or bus participation (henceforth-called participation factor).

If $\Phi_{i}$ and $\Gamma_{i}$ represent the right- and left- hand eigenvectors, respectively, for the eigenvalue $\lambda_{i}$ of the matrix $J_{R}$, then the participation factor measuring the participation of the $\mathrm{k}^{\text {th }}$ bus in $\mathrm{i}^{\text {th }}$ mode is defined as

$$
P_{k i}=\Phi_{k i} \Gamma_{i k}
$$

Note that for all the small eigenvalues, bus participation factors determine the area close to voltage instability.

Q-V CURVES: The Q-V curves are used in this voltage stability study since they directly assess shortage of reactive power. The Q-V curves (reactive power-voltage curves) technique is a more general method of assessing voltage stability. These curves are presently the workhorse method of voltage stability assessment for many utilities. Q-V curves show the sensitivity and variation of bus voltages with respect to the reactive power injection. A typical Q-V curve is shown in Figure 2(b). The Q axis shows the reactive power that needs to be added or removed from a bus to maintain a given voltage at a given load. From

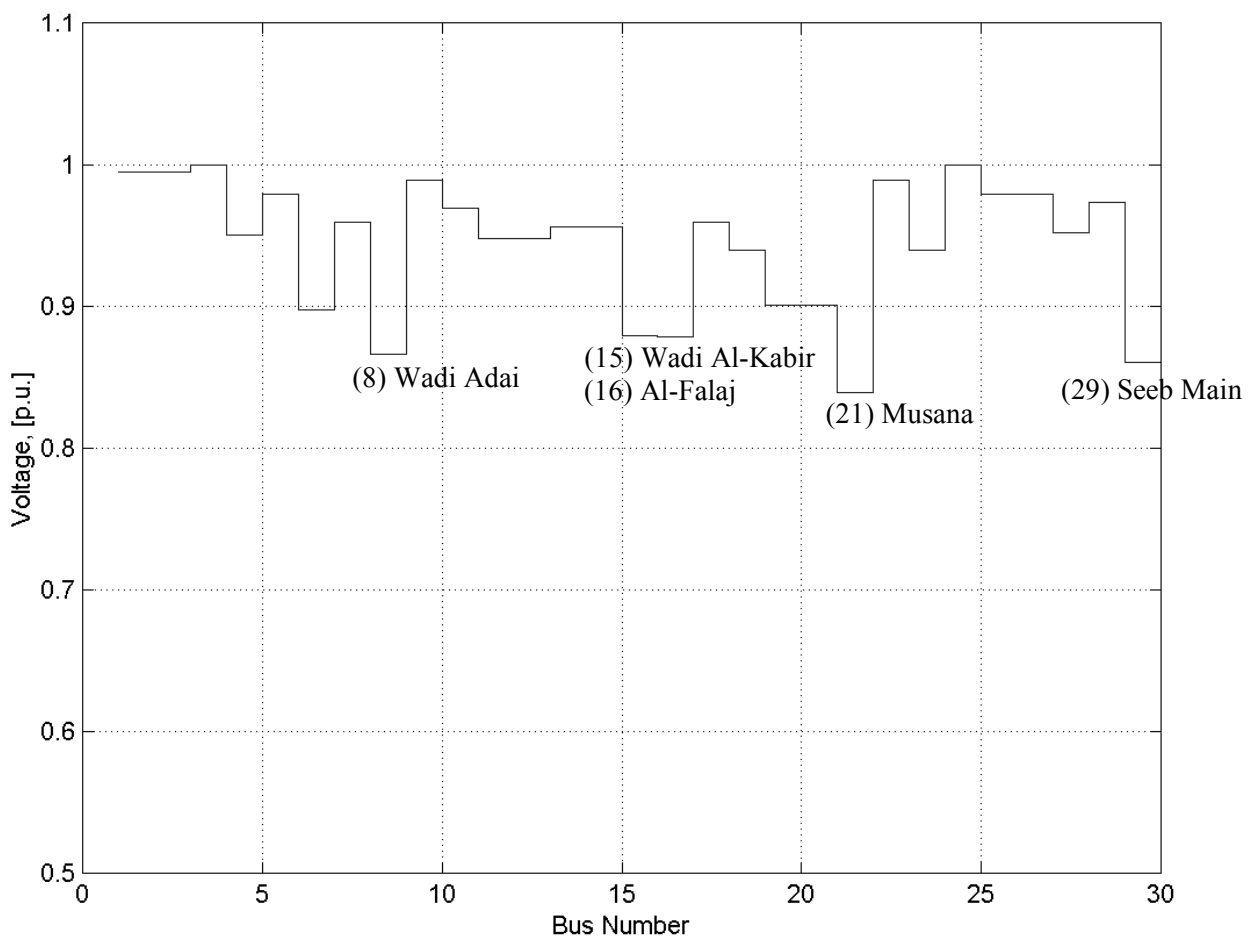

Figure 3 . System voltage profile for the base case

Figure 2(b), it can be seen that the curve gives reactive power margin at the test bus. The reactive power margin is the MVAr distance from the operating point to the most right point of the curve. This curve can be used as an index for voltage instability ( $\mathrm{dQ} / \mathrm{dV}$ becomes negative). Near the nose of the $\mathrm{Q}-\mathrm{V}$ curve, 


\section{VOLTAGE STABILITY ANALYSIS OF MUSCAT POWER SYSTEM}

sensitivities get very large and then reverse their sign. The Jacobian matrix becomes singular at the nose of the curve. This is called a saddle bifurcation node (Yokoyama and Sekine, 1989).

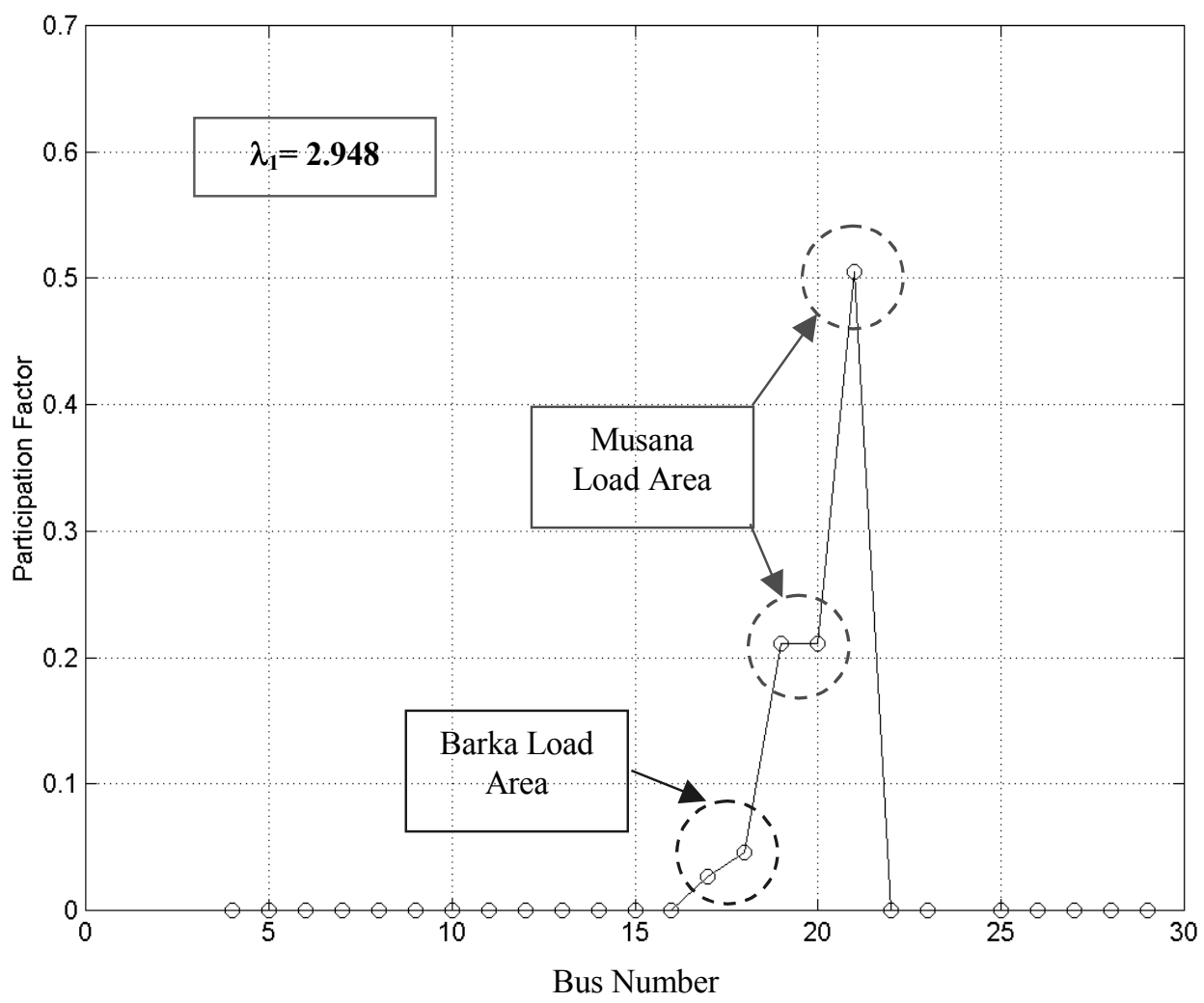

Figure 4. Participation factors of the most critical mode eigenvalue $\lambda=2.948$ for the base case.

P-V CURVES: The power-curves (P-V) curves are the most widely used method of estimating voltage security, providing megawatt (MW) margin type indices. The P-V curve is used to determine the MW distance from the operating point to the critical voltage. A typical P-V curve is shown in Figure 2(a). The P$\mathrm{V}$ curves are also useful for conceptual analysis when the load characteristics as a function of voltage are analyzed. While PV-curves are helpful in understanding the phenomena of voltage stability and collapse, they are not useful for determining the reactive power support needed at various points in a power system.

\section{The Results}

The summer peak loads of the year 1998 are taken as a base case study for the existing Muscat power system. The system is designed to serve the load demand at nominal voltage and all voltages are required to be within specific limits. The MVA base value is taken equal to 100 MVA.

The voltage profile obtained from the power flow solution of the base case condition is shown in Figure 3. Rusail generation bus (bus 3) was taken as the slack bus. Manah and Ghubrah generation buses (buses 1, 2 and 24) were considered as P-V buses. All generating units are operating on their rated power. Constant power loads represent the loads. From Figure 3, it can be seen that the voltage of the heavy load buses, specifically Musana load bus (bus 21) is not within the specified limit $\pm 10 \%$. The low voltages of these heavy load buses are due to the induction motor loads (air conditioning).

The modal analysis method was applied to identify the voltage collapse areas in Muscat power system for the base case. The eigenvalues of the Jacobian matrix $J_{R}$ for the base case were computed and all the eigenvalues are positive, indicating that the system is voltage stable for the base case. It was observed that all the eigenvalues are real. This observation agrees with the fact that voltage collapse is monotonic. The critical eigenvalues for the base case are shown in Table 1. While not reported in this paper, the critical eigenvalues were compared with the minimum singular values (MSVs) decomposition (Löf et al, 1993) of the Jacobian matrix $J_{R}$ and the results obtained agreed with each other. The MSVs were computed using MATLAB. 


\section{ELLITHY, GASTLI, AL-ALAWI, AL-HINAI and AL-ABRI}

Table 1: Most Critical eigenvalues

\begin{tabular}{|c|c|c|}
\hline \multicolumn{3}{|c|}{ Eigenvalues $\lambda$} \\
\hline Base Case & Bus 21 Stressed & Bus 18 Stressed \\
\hline 6.003 & 6.003 & 4.750 \\
\hline 4.750 & 4.750 & 3.833 \\
\hline 3.833 & 3.833 & 2.914 \\
\hline 2.948 & 0.042 & 0.099 \\
\hline
\end{tabular}

The bus participation factors corresponding to the most critical mode eigenvalue $(\lambda=2.948)$ for the base case are shown in Figure 4. The large participation factor value (0.5) indicates a high involvement of the bus to voltage collapse. The participation factors shown in Figure 4 indicate that buses 19, 20, 21, 18, and 17 (key buses in South Batna area) are the buses with the highest participation factors to the critical mode. These buses are the most critical in maintaining the voltage stability of the critical mode.

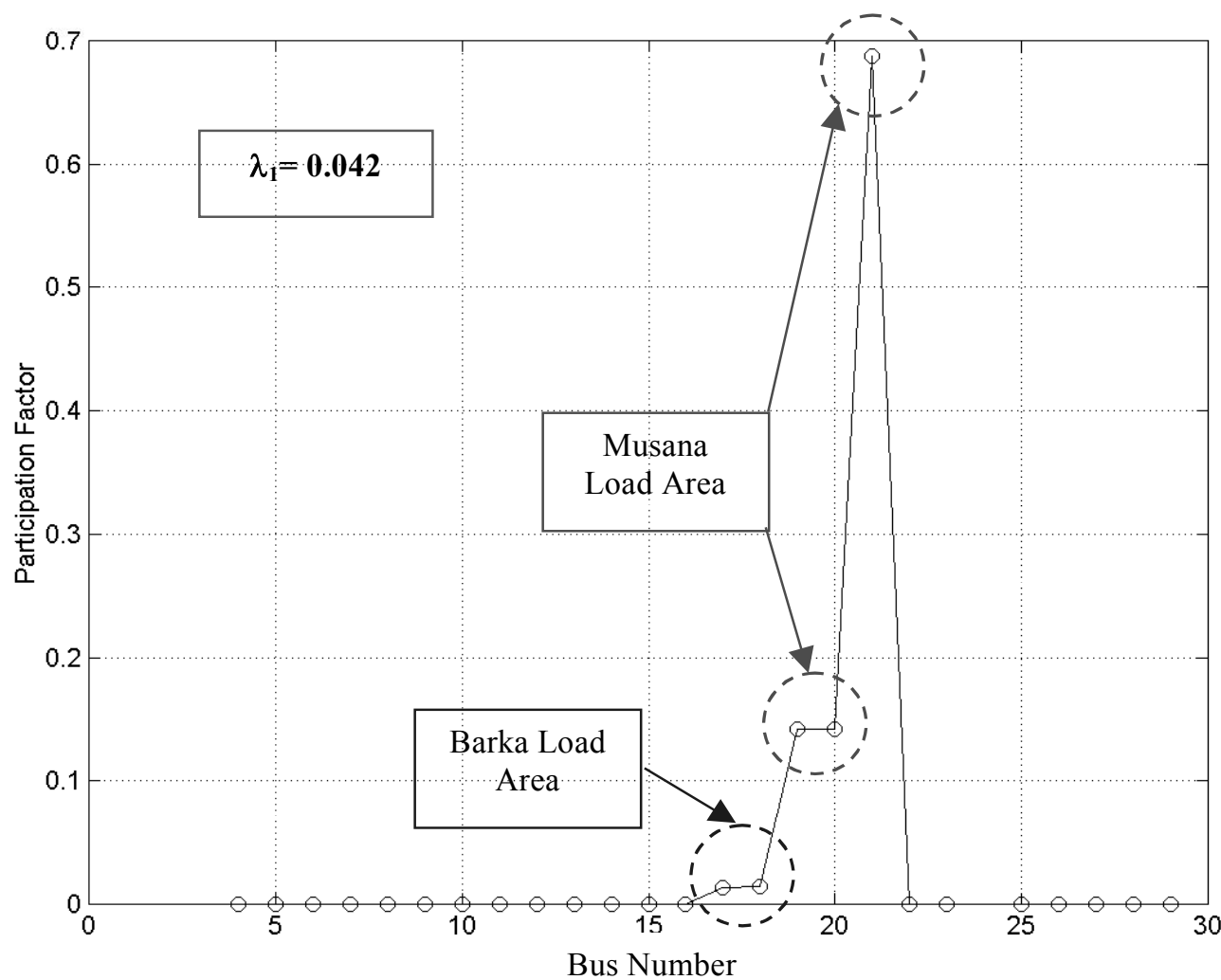

Figure 5. Participation factors of critical mode eigenvalue $\lambda_{1}=0.042$ for load demand increase at Musana area from 65MVAr-base (0.65 pu) up to 142.75MVAr (1.4275 pu)

The load buses 21 and 18 (Musana and Barka load buses) in South Batna area were stressed with increased reactive power load respectively. The near-nose points computed with the stressed power-flow were then analyzed using modal analysis. The critical eigenvalues for the stressed case are listed in Table 1. From Table 1, it can be concluded that the power stress in South Batna load area can lead to voltage instability (eigenvalue $\lambda \approx 0$ ). Figure 5 illustrates the participation factors of the most critical mode eigenvalue for all buses. It can be seen that the key buses of South Batna load area have the largest participation factors, and hence is the area vulnerable to voltage collapse.

The P-V curves and Q-V curves were computed for the weakest load buses (buses 18 and bus 21) at the South Batna area. The curves are shown in Figures 6, 7 and 8. These curves are used to determine the MWand MVAr-distance to voltage instability point (voltage stability margins) of the weakest load buses of 
South Batna area. Their margins were determined between the maximum loading point and the base case loading. Their margins are given in Table 2.

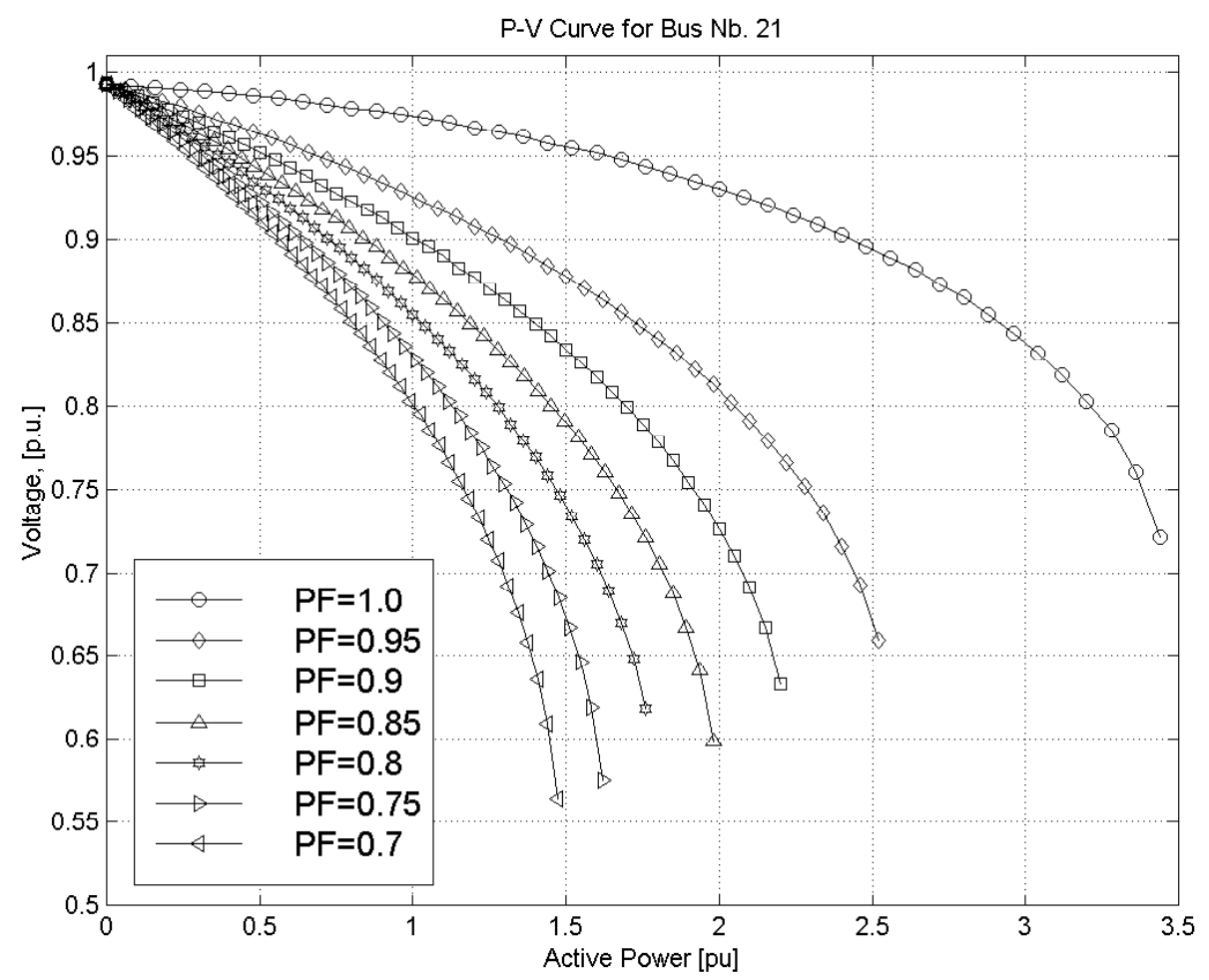

Figure 6. P-V curves for bus 21

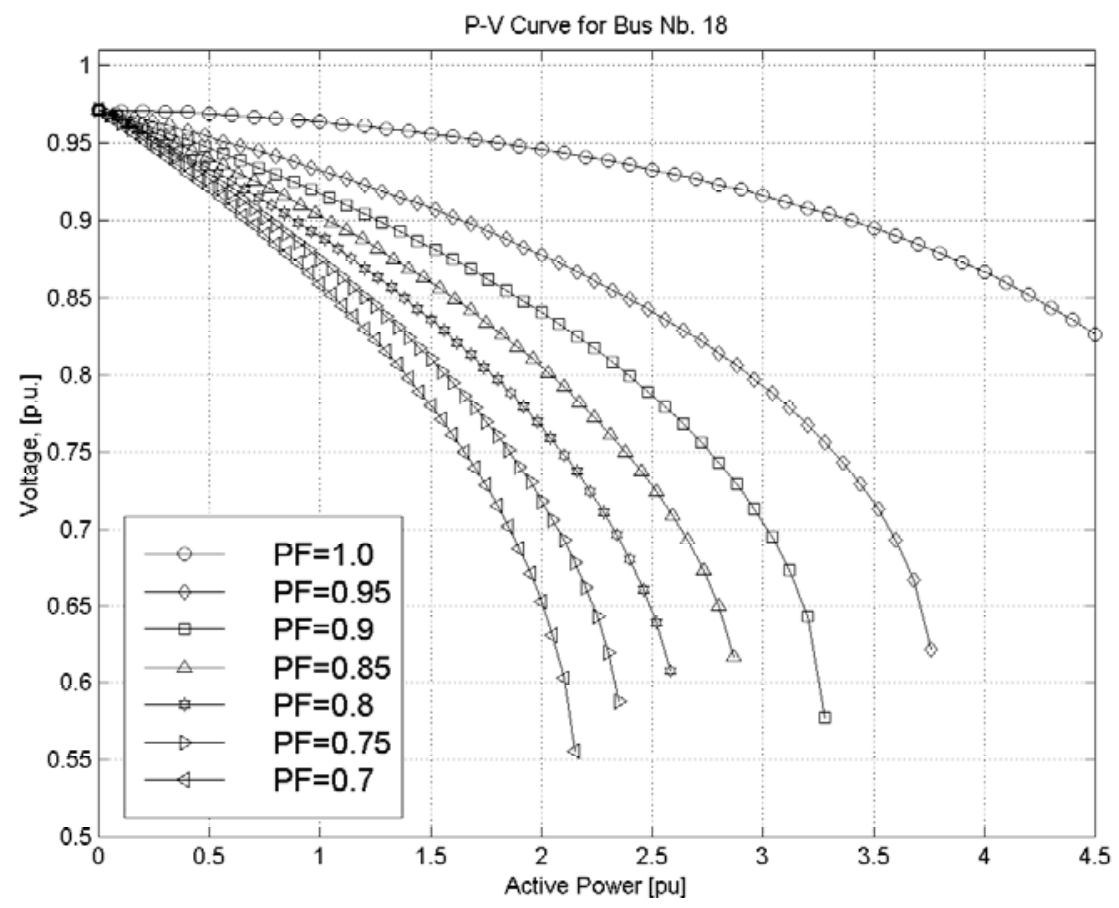

Figure 7. P-V curves for bus 18 
ELLITHY, GASTLI, AL-ALAWI, AL-HINAI and AL-ABRI

Table 2: MVAr and MW margins of the weakest load buses

\begin{tabular}{|c|c|c|c|c|c|}
\hline $\begin{array}{c}\text { Bus } \\
\text { number }\end{array}$ & $\begin{array}{c}\text { Load bus } \\
\text { name }\end{array}$ & $\begin{array}{c}\text { MVAr base } \\
\text { (p.u) }\end{array}$ & $\begin{array}{c}\text { MW base } \\
\text { (p.u) }\end{array}$ & $\begin{array}{c}\text { MVAr margin } \\
\text { (p.u) }\end{array}$ & $\begin{array}{c}\text { MW margin } \\
\text { (p.u) }\end{array}$ \\
\hline 21 & Musana & 0.650 & 1.650 & 0.778 & 1.140 \\
\hline 18 & Barka & 0.250 & 1.000 & 2.330 & 3.900 \\
\hline
\end{tabular}

The calculated MW and/or MVAr margins indicate how close the current operating point of the system is to the voltage instability point i.e. how much active and/or reactive load can be added to the weakest load buses before the voltage instability occurs. The calculated MVAr margins could relate to the size of shunt capacitors or static VAr compensators in the load areas (Mansour et al, 1992; Vaahedi et al, 1999).

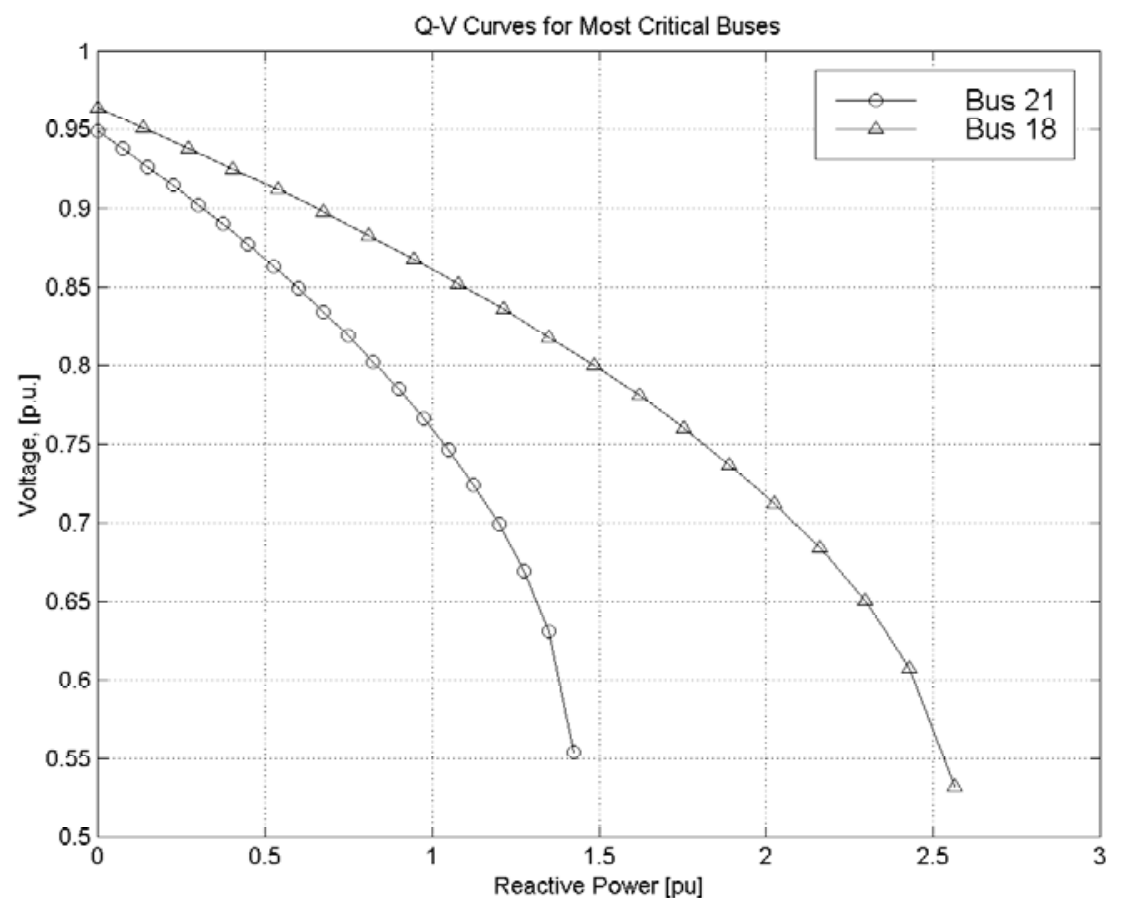

Figure 8 . Q-V curves for bus $21 \& 18$

\section{Conclusions}

A preliminary study of voltage stability for Muscat power system was presented in this paper. The analysis is based on the summer peak loads conditions of the year 1998. The weak load areas, which could lead to voltage instability, were identified using the modal analysis technique. The system bus participation factors of the critical mode were used to determine the load area, which contributes to voltage instability. It was found that South Batna area is the weakest load area in the system, which could lead to voltage collapse. The MW- and MVAr-distance from the operating condition to the voltage instability point (voltage stability margins) for the weakest load areas have been determined from the P-V Curves and Q-V curves. These margins are an essential tool for voltage stability and security assessment. The extension of the results of this research work to address the security assessment of the system voltage stability and the shunt compensations for system voltage support are the subject of a future work. 


\section{VOLTAGE STABILITY ANALYSIS OF MUSCAT POWER SYSTEM}

\section{Acknowledgment}

The authors acknowledge the support from the Ministry of Electricity \& Water and Sultan Qaboos University. The authors also wish to express their appreciation for the senior engineers of the Ministry in the control center for their useful comments during the course of this project.

\section{References}

AJJARAPU, V and LEE, B. 1998. Bibliography on Voltage Stability. IEEE Trans. on Power Systems, 13: 115-125.

BEGOVIC, M.M. and PHADKE, A.G. 1992. Control of Voltage Stability Using Sensitivity Analysis. IEEE Trans. on Power Systems, 7: 114-123.

CIGRE TASK FORCE 38.02.10. 1993. Modeling of Voltage Collapse Inducing Dynamic Phenomena.

CUTSEM, T. 1991. A Method to Compute Reactive Power margins with respect to Voltage. IEEE Trans. on Power Systems, PWRS-6: 145-156.

D'AQUILA, R., MILLER, N. W. JIMMA, K. M., SHEHAN, M.T. and COMEGYS, G.L. 1993. Voltage stability of the Puget Sound System under Abnormally Cold Weather Conditions. IEEE Trans. on Power Systems, 8: 1133-1142.

DeMACRO, C. and OVERBYE, T. 1990. Energy based security Measure for Assessing Vulnerability to Voltage Collapse. IEEE Trans. on Power Systems, 5: 419-427.

El-KEIB, A. and MA, X. 1995. Application of Artificial Neural Networks In Voltage Stability Assessment. IEEE Trans. on Power Systems, 10: 1890-1896.

FLTABO, N. and DOMMEL, H. 1990. Voltage Stability Condition in a Power Transmission System calculated by Sensitivity Methods. IEEE Trans. on Power Systems, 5: 1286-1293.

GAO, B., MARISON, G. and KUNDUR, P. 1992. Voltage Stability Evaluation Using Modal Analysis. IEEE Trans. on Power Systems, 7: 1423-1543.

IEEE SPECIAL BUBLICATION 90TH0358-2-PWR. 1990. Voltage Stability of Power Systems: Concepts, Analytical Tools, and Industry Experience.

JESASURYA, B. 1990. Application of Artificial Neural Networks In Voltage Stability Evaluation. Electric Power Systems Research, 29: 85-90.

LIU, C., CHANG, C. and SU, M. 1998. Neuro-Fuzzy Networks for Voltage Security Monitoring based On Synchronous Pharos Measurements. IEEE Trans. on Power Systems, 13: 326-332.

LöF, P.A., ANDERSON, G. and HILL, D.J. 1993. Voltage Stability Indices for Stressed Power System. IEEE Trans. on Power Systems, 8: 326-335.

LöF, P.A., SMED, T., ANDERSON, G. and HILL, D.J. 1992. Fast Calculation of a Voltage Stability Index. IEEE Trans. on Power Systems, 7: 54-64.

MANSOUR, Y., XU, W., ALVERADO, F. and RINZIN, C. 1994. SVC Placement Using Critical Modes of Voltage Instability. IEEE Trans. on Power Systems, 9: 757-763.

MORRISON, G., GAO, G. and KUNDUR, P. 1993. Voltage Stability Analysis Using Static and Dynamic Approaches. IEEE Trans. on Power Systems, 8: 1159-1171.

OVERBYE, T. and DeMACRO, C. 1995. Improved Power System stability Assessment Using Energy Method. IEEE Trans. on Power Systems, 6: 1890-1896.

PAL, P. 1992. Voltage Stability Conditions Considering Load Characteristics. IEEE Trans. on Power Systems, 7: 243-249.

SCHLUETER, R. 1998. A Voltage Stability Security Assessment Method. IEEE Trans. on Power Systems, 13: 1423-1438.

STEWART, W. and JENNINGS, A. 1981. A Simultaneous Iteration Algorithm for Real matrices. ACM Trans. on Mathematics Software, 7: 184-198.

SUZUKI, M., WADA, S., ASANO, T. and KUDO, K. 1992. Newly Developed Voltage Security Monitoring System. IEEE Trans. on Power Systems, 7: 965-972.

TAMURA, Y., MORI, H. and IWAMOTO, S. 1982. Relationship between Voltage Stability and Multiple Load Flow Solutions in Electric Systems. IEEE Trans. on Power Apparatus and Systems, PAS-102: 1115-1123.

TAYLOR, C. W. 1994. Power System Voltage Stability. McGraw-Hill, New York.

VAAHEDI, E., FUCHS, C., Xu W., MANSOUR, Y., HAMADANIZADEH, H. and MORISON, G. 1999. Voltage Stability Contingency Screening and Ranking. IEEE Trans. on Power Systems, 14: 256-265.

VAAHEDI, E., MANSOUR, Y. and SUN, D. 1999. Large Scale Voltage Stability Constrained Optimal Planning and Voltage Stability Applications Using Existing OPF/Optimal Var Planning Tools. IEEE Trans. on Power Systems, 14: 65-74

VERGHES, G., PEREZ-ARRIAGA, I. and SCHEWWPPE, F. 1982. Selective Modal Analysis with Application to Electric Power systems-Part II. IEEE Trans. on Power App. and Systems, PAS 101: 3117-3134.

YOKOYAMA, A. and SEKINE, Y. 1989. A Static Voltage Stability Index Based On Multiple Load Flow Solutions. Proc. of the Bulk Power System Voltage- Phenomena Stability and Security, Missouri. 